\title{
Evaluation of Hydrological Data Collection Challenges and Flood Estimation Uncertainties in Nigeria
}

\author{
Iguniwari Thomas Ekeu-wei ${ }^{1}$ \\ ${ }^{1}$ Lancaster Environment Centre, Lancaster University, Lancaster, United Kingdom \\ Correspondence: Iguniwari Thomas Ekeu-wei, Lancaster Environment Centre, Lancaster University, Lancaster, \\ LA1 4YQ, United Kingdom. Tel: 234-812-097-0000. E-mail: i.ekeu-wei@lancaster.ac.uk
}

Received: April 6, 2018

Accepted: April 11, 2018

Online Published: April 23, 2018

doi:10.5539/enrr.v8n2p44

URL: https://doi.org/10.5539/enrr.v8n2p44

\begin{abstract}
In recent years, flooding has become a recurring problem in many regions including Nigeria, owing to changing climatic conditions, as well as anthropogenic factors such as poor land use management and urbanization that aggravate flood impact. To effectively manage and mitigate flood impact, hydrological data is required, and in many developing regions gauging stations are established, and gauge readers recruited and trained to collect and transmit such data to designated hydrological or water resource management agencies. This study focuses on understanding the challenges associated with hydrological data collection in Nigeria, using the Ogun-Osun River as a typical case, while analytically assessing how these challenges result in uncertainties that propagate unto flood frequency estimates that are used to inform flood management decisions. The findings reveal that (i) capacity and institutional gaps; lack of maintenance of hydrological infrastructure and surrounding landscape; poor data management architecture; and floods events that destroy hydrological equipment and inundate roads thereby restricting access to collected data during peak floods, are some of the challenges associated with hydrological data collection in developing regions; (ii) these conditions result in gaps in and shortened length of annual maximum hydrological time series required for flood frequency estimation, consequently leading to under or overestimation of low and high flood quantiles such as 1-in-2year and 1-in-100year floods, to levels of $0.67 \mathrm{~m}$ and $0.9 \mathrm{~m}$ respectively for the Ogun Osun River Basin. The need for improved data collation, management and adaptation of new technologies such as radar or sonar by the Ogun-Osun River Basin Development Authority is recommended in this study, to ensure sustainable and improved hydrological data collection, management, transferability and usability for flood management.
\end{abstract}

Keywords: Hydrological data collection, HYDROMET, Flooding Frequency Analysis, Uncertainties

\section{Introduction}

Floods are one of the most devastating natural hazards, increasing in frequency, magnitude and impact in recent decades (Aerts et al., 2014; Di Baldassarre et al., 2010), owing to changing climatic conditions and anthropogenic factors such as poor land use management and urbanization (Lavender \& Matthews, 2009). Reliable flood information is required by the government and other stakeholders alike to inform the deployment of flood countermeasures to mitigate flood impact (Padi, Baldassarre, \& Castellarin, 2011). Typically, networks of Hydro-Meteorological (HYDROMET) gauging stations are established for systematic data collection (Herschy, 2008; Hipel, 1995), distributed across locations of interest for continuous and long-term data collection. Nevertheless, operating these stations, especially in developing regions is challenging, as factors such as poor financing by the government (Starrett et al., 2010), poor institutions, lack of commitment, lack of capacity, logistical and technical challenges (Ampadu, Chappell, \& Kasei, 2013; Olayinka, Nwilo, \& Emmanuel, 2013) hamper seamless data collection. These challenges result in hydrological gauging stations inadequacy, declining functionality, and gaps in available data, which would result in uncertain flood estimates and consequently poor flood management decisions if left unchecked. This paucity of data is particularly severe in developing countries, thereby further limiting these nations capacity to mitigate and cope with the impact of flooding on people, environment, infrastructure and socio-economic activities (Komi, Neal, Trigg, \& Diekkrüger, 2017).

In the Ogun-Osun River Basin, the study area for this research, citizen observatory is typically employed, whereby, local residents are recruited and trained to collect and record daily water level readings (i.e. Gauge Readers (GR)), then records are transmitted intermittently to a designated hydrological data collation officer of 
the river basin authority (Bashiru, 2015). Like many developing regions, river measurements are manually collected using staff gauges and later converted to discharge using an established rating curve (Herschy, 2008). Therefore, during the peak of floods, measurement equipment could be damaged and/or access roads inundated, thereby impeding continuous data collection (Dano Umar et al., 2011; Olayinka et al., 2013).

These challenges result in measurement errors, gaps in and shortened length of historical hydrological time series data, and are known to contribute to flood frequency estimate uncertainty, especially for the standard 1-in-100year flood estimates widely used for flood management planning and design of hydraulic structure such as dykes and levees to mitigate flood impact (Feaster, 2010). These measurement (aleatory) uncertainties are further exacerbated by procedural (epistemic) uncertainties that could result from the subjective nature of determining optimal probability distribution and parameters (such as shape, scale and location) required in the flood frequency estimation process (Di Baldassarre, Laio, \& Montanari, 2012; Laio, Di Baldassarre, \& Montanari, 2009).

This study seeks to understand the challenges associated with hydrological data collection in a typical developing region, with the specific objectives of:

1) Developing knowledge of the factors that contribute to the challenges associated with hydrological data collection in developing regions; and

2) Analytically assessing how these factors contribute to data uncertainty that consequently propagates onto flood model outcomes and decisions.

\section{Study Area}

The study area (Figure 1), Ogun-Osun River Basin (OORB) is located in western Nigeria $\left(6^{\circ} 30^{\prime}-8^{\circ} 20^{\prime} \mathrm{N}\right.$ latitude and $3^{\circ} 23^{\prime}-5^{\circ} 10^{\prime} \mathrm{E}$ longitude), and encircles four states including Ogun, Osun, Oyo and Lagos, within a $66,264 \mathrm{~km}^{2}$ area. The basin is drained by two major tributaries, Ogun and Osun, and other minor tributaries including Yewa, Ibu, Ona, Sasa and Ofiki Rivers. The climate of OORB is influenced by tropical continental and maritime air masses (Adeaga, Oyebande, \& Depraetere, 2006), and experiences an annual rainfall of $1400 \mathrm{~mm}$ to $1500 \mathrm{~mm}$; mean annual air temperature between $25.7^{\circ} \mathrm{C}$ and $30^{\circ} \mathrm{C}$; and relative humidity varying from $37 \%-85 \%$ for dry and wet seasons respectively (Adeleke et al., 2015). The OORB experiences recurring flooding, caused by factors such as intense precipitation; poor urban planning and waste management; and failure of upstream hydraulic systems, resulting in socio-economic, infrastructural, ecological and environmental impacts (Jinadu, 2015; Komolafe, 2015). The five (5) locations under investigation for this study are along the Yewa River and include, Ajilete, Ebute - Igbooro, Eggua, Idogo and Ijaka - Oke, and are managed by the Ogun Osun River Basin Development Authority (OORBDA).

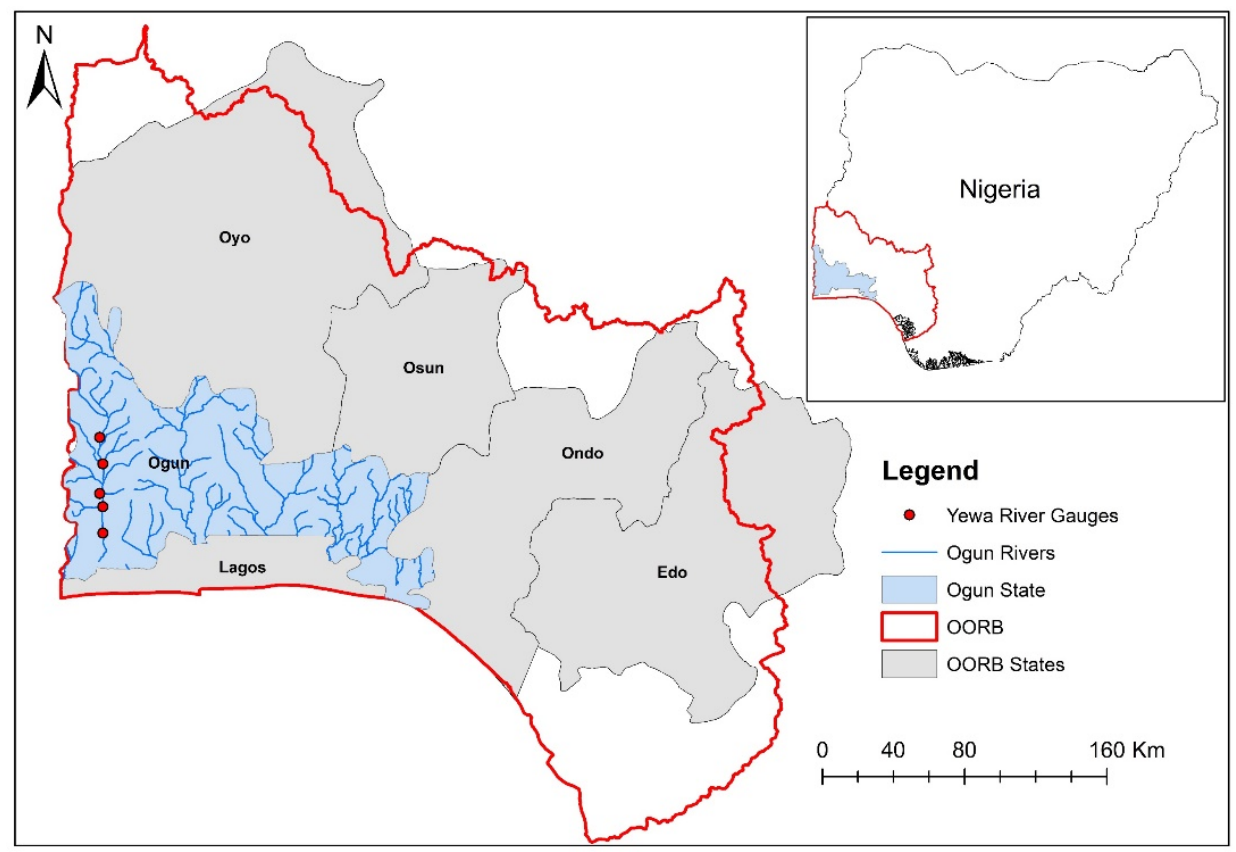

Figure 1. Study area showing OORB, constituting states and gauging station locations along Yewa River 


\section{Methodology}

\subsection{Qualitative and Quantitative Data Collection and Analysis}

A combined qualitative and quantitative approach is adopted in this study, where locally recruited hydrological data collection officers (gauge readers) were interviewed as part of a hydrographic survey and data collection campaign in January 2015. The five (5) gauge readers interviewed were responsible for Ajilete, Ebute - Igbooro, Eggua, Idogo and Ijaka - Oke hydrological gauging stations located along the Yewa River, one of the major rivers in Ogun state Nigeria. Direct quotations of gauge readers are presented in italics in Section

4. Analysis and Discussions. Also, field observation notes and photos were taken during the visit, and historical hydrological data acquired from the OORBDA were analysed using FLIKE Software (Kuczera, 1999) to corroborate interviewee disclosure and examine the uncertainties associated with gaps hydrological data collected from gauging stations presented in Table 1 .

Table 1. Properties of hydrological data collection (Source: OORBDA)

\begin{tabular}{cccccccc}
\hline S/N & Station Name & $\begin{array}{c}\text { Latitude } \\
(\mathrm{N} / \mathrm{S})\end{array}$ & $\begin{array}{c}\text { Longitude } \\
(\mathrm{E} / \mathrm{W})\end{array}$ & Date Established & $\begin{array}{c}\text { Duration } \\
(\text { Years })\end{array}$ & No of Missing Data & Station Type \\
\hline 1 & Ijaka Oke & 7.183333 & 2.900000 & 1980 & $1980-2012(32)$ & 5 & Staff Gauge (Note 1) \\
2 & Eggua & 7.050000 & 2.916667 & 1982 & $1982-2012(30)$ & 4 & Staff Gauge \\
3 & Ebute Igboro & 6.900000 & 2.900000 & 1980 & $1980-2012(32)$ & 7 & Staff Gauge \\
4 & Idogo (Note 2) & 6.833333 & 2.916667 & 1982 & $1982-2012(30)$ & 6 & Staff Gauge \\
5 & Ajilete & 6.700000 & 2.916667 & 1980 & $1980-2012(32)$ & 2 & Staff Gauge \\
\hline
\end{tabular}

\subsection{Missing Data Imputation and Flood Frequency Analysis}

To evaluate the effect of missing data on flood frequency estimates, two datasets are developed and used for flood frequency analysis, (i) with missing data removed and (ii) with missing data filled using multiple imputation implemented in R using the Amelia package (Honaker, King, \& Blackwell, 2011). The Multiple Imputation missing data infilling methodology uses the Markov Chain Monte Carlo approach that estimates missing values by randomly sampling from a distribution of plausible values derived from multiple simulations undertaken using mean and standard error parameters similar to that of the original dataset, under the assumption of normal distribution (van Buuren, 2007). This approach quantifies the uncertainty in the simulation process and reduces false precision attainable with single imputation ( $\mathrm{Li}$, Stuart, \& Allison, 2015). Flood frequency analysis (FFA) was undertaken using Flike software (Kuczera, 1999) by fitting a predetermined probability distribution (i.e. the Generalized Extreme Value (GEV)) to the annual maximum flow time series for Idogo (the case site used for this analysis, having the least historical record due to missing records). The GEV probability distribution is selected for simplicity, based on its widespread usability in various regions (Izinyon \& Ehiorobo, 2014; Smith, Villarini, \& Baeck, 2011; Villarini \& Smith, 2010) and for consistency with previous studies in the area investigated (Awokola \& Martins, 2001; Ewemoje \& Ewemooje, 2011). Typically, a suitability analysis can be undertaken to determine the probability distribution that best fits the time series data (Laio et al., 2009).

GEV formula is expressed in equation 1 as follows:

$$
\mathrm{F}(\mathrm{x} \mid \tau, \alpha, \kappa)=\left\{\begin{array}{l}
\frac{1}{\alpha} \exp \left\{-\left[1-\frac{\kappa(\mathrm{x}-\tau)}{\alpha}\right]^{\frac{1}{\kappa}}\right\}\left[1-\frac{\kappa(\mathrm{x}-\tau)}{\alpha}\right]^{\frac{1}{\kappa}-1} \text { when }<0, \mathrm{x}<\tau+\frac{\alpha}{\kappa} ; \text { when } \kappa<0, \mathrm{x}>\tau+\frac{\alpha}{\kappa} \\
\frac{1}{\alpha} \exp \left[-\frac{(\mathrm{x}-\tau)}{\alpha}\right] \exp \left\{-\exp \left[-\frac{(\mathrm{x}-\tau)}{\alpha}\right]\right\} \text { if } \kappa=0
\end{array}\right.
$$

where, $\tau, \alpha$, and $\mathrm{k}$ represents location, scale and shape parameters of the distribution function, presented in Table 2 .

Table 2. Parameters of the GEV probability distribution function

\begin{tabular}{lcc}
\hline Parameters & Gaps removed & Gaps filled \\
\hline Location $(\tau)$ & 12.0368 & 11.5529 \\
Scale $(\alpha)$ & 0.1488 & 0.5231 \\
Shape $(\mathrm{k})$ & 1.1906 & 0.3778 \\
\hline
\end{tabular}




\section{Analysis and Discussions}

\subsection{Challenges Associated with Hydrological Data Collection in Typical Developing Regions}

River discharge data is a fundamental input (initial and boundary condition) required for flood modelling. River water levels within the study area are typically measured using staff gauge, then converted to discharge using established rating curves that plot water levels against discharge (Di Baldassarre et al., 2012; Herschy, 2008); see Supplementary Figure 1 for Idogo rating curve. This data collection approach results in measurement and extrapolation uncertainties (Baldassarre \& Montanari, 2009; Haque, Rahman, \& Haddad, 2014). Also, during peak flood seasons, access to remote areas for data collection is usually restricted due to inundation, and in some cases, hydrological measurement equipment are damaged by high-intensity floods (Olayinka et al., 2013). The Eggua GR recalled how the 2007 flood event resulted in the damage the gauging station, stating that "the flood $27^{\text {th }}$ of July 2007, destroyed the gauge station", with water levels reaching a peak of approximately "4.2 metres". These disclosures were consistent with a recent study in the region (Adelekan, 2011), as well as records from the Dartmouth Flood Observatory, Global Active Archive of Large Flood Events records (Note 3), where 1997, 1999 and 2007 flood events were reportedly caused by heavy rainfall, affected parts of Ogun state, damaging infrastructure and displacing approximately 5,000 persons in 2007 .

In other instances, high magnitude flood events inundated road networks, thereby restricting the movement of manual data collectors. The GR's for Ajilete, Ijaka-Oke and Ebute Igboro also recalled that water levels overtopped roads and bridges, resulting in the absence of peak flow data. The Idogo GR narrated how the "1997 and 1999 flood events resulted in river overtopping the bridge, thus restricting passage of goods and persons", while Ijaka-Oke GR recalled that "... The water level is enlarged during the rainy season", thereby restricting of movement ".... when the water comes, nobody can come from Ayetoro to this place, ...we are leaving at Ijaka, no way to move from Ijaka to anywhere else..., water close the road, there is no sign to move anywhere...". "...if I'm not swimming, there is no way to go to another place...".

Lack of financial support, technical deficiency, obsolete equipment/infrastructure and poor institutions have also been identified as some of the factors responsible for hydrological data sparsity in Nigeria (Ertuna, 1995; Izinyon \& Ehiorobo, 2014; Olayinka et al., 2013; Olomoda, 2012). Furthermore, Maxwell (2013) and Ononiwu, (1994) attributed data inconsistency to poor hydrological data management systems and lack of standards, which results in data unreliability, fabrication and data format inconsistencies. The GR at Ijaka-Oke disclosed the need for an increase in his salary, stating "... I need the government to increase my salary", and the GR at Eggua similarly lamented non-payment for some time. Also, given that some of the GR's could not communicate in English, while others could, it was evident that the level of education or exposure varied amongst the gauge readers, although this question was not specifically asked. However, some of the GR's, like that at Ebute Igboro have been collecting data for the OORBDA since the inception of the gauging station in "1983/1984", hence there is some consistency in the data collection process, capacity and knowledge development over time.

Additionally, Maxwell (2013) and Olayinka (2012) argued that even when data is available, custodians store data in paper formats, thus limiting transferability, applicability and long-term/sustainable data availability. A sample dataset collected from the Ogun-Osun River Basin Authority is presented in Figure 2, showing the typical paper-based data collation and storage format by the agency. Such datasets and formats are prone to data quality error during imputation, typographical and data conversion errors during data transfer from paper to digital format (Beall, 2006). Figure 3 shows the gaps in time series of annual peak flows (discharge), likely caused by the absence of data due to the factors highlighted above. 


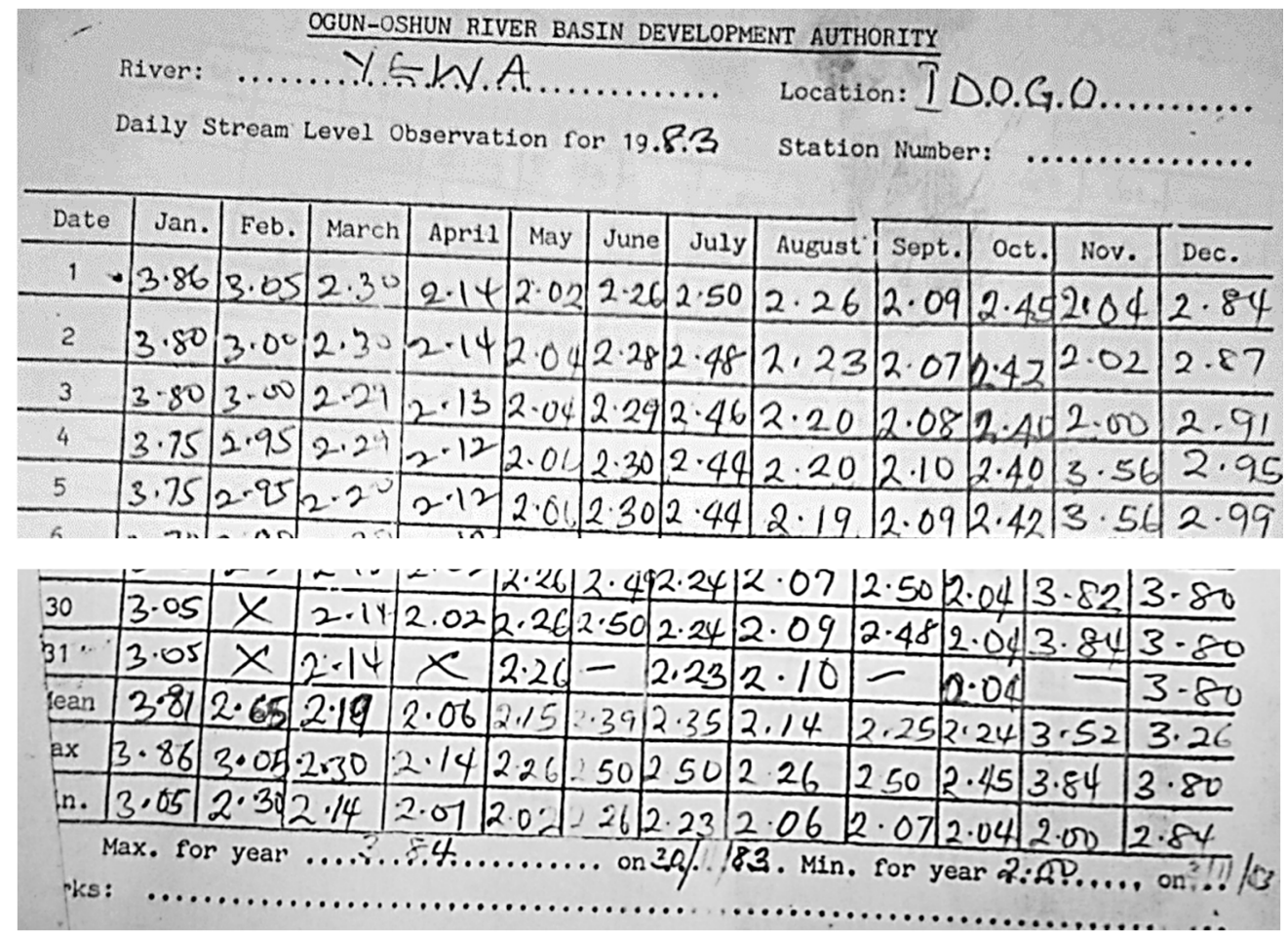

Figure 2. A sample of paper-based hydrological data storage format (Source: OORBDA)

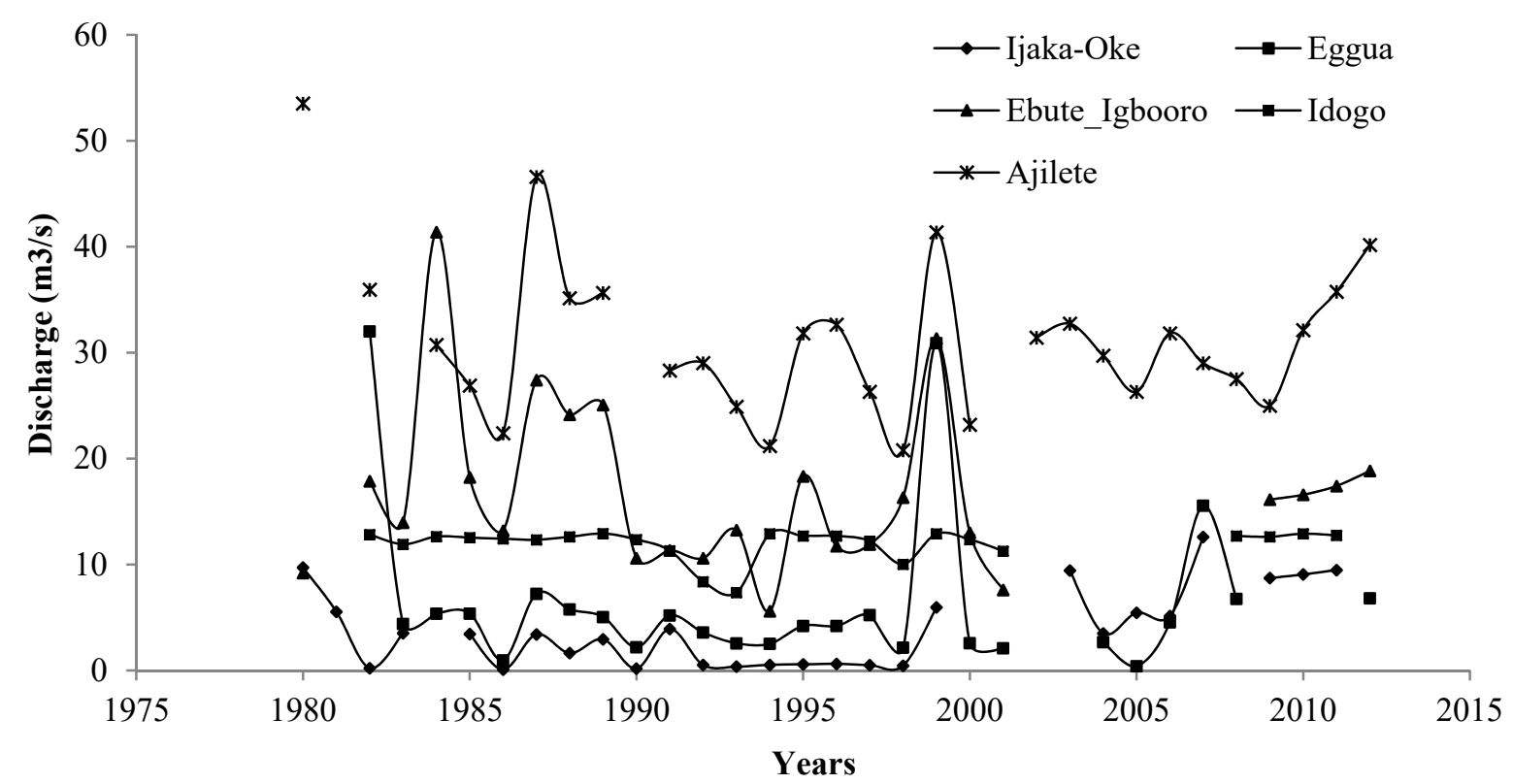

Figure 3. Time series plot of peak flows (discharge) for the five gauging stations investigated (Source: OORBDA)

Furthermore, field observations revealed restricted access to staff gauges, to degrees that could affect the effective reading of staff gauge measurements and consequently result in uncertainties that are aleatory in nature, i.e. due to measurement (Merz \& Thieken, 2005). Figure 4 (A) and (B) shows such instances at Idogo and Ebute Igboro respectively, revealing the need for vegetation clearance and maintenance of staff gauge and surrounding landscape. 


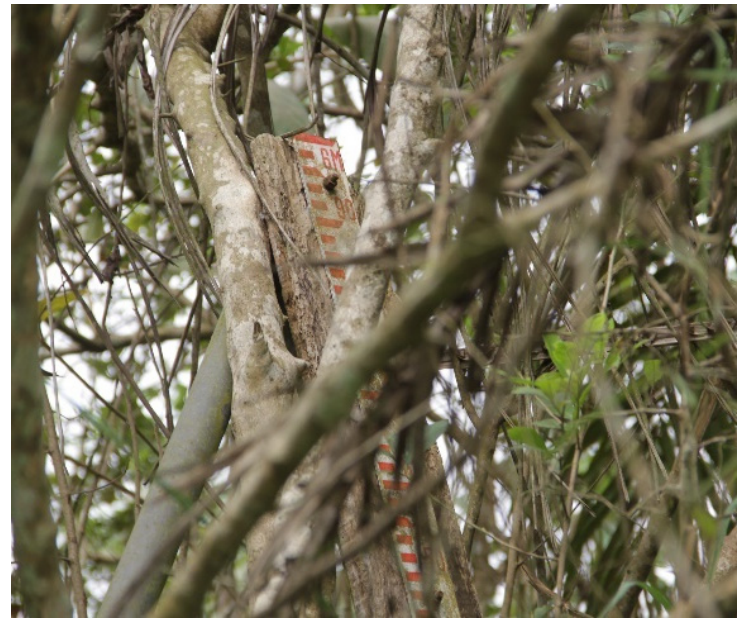

A. Staff gauge at Idogo

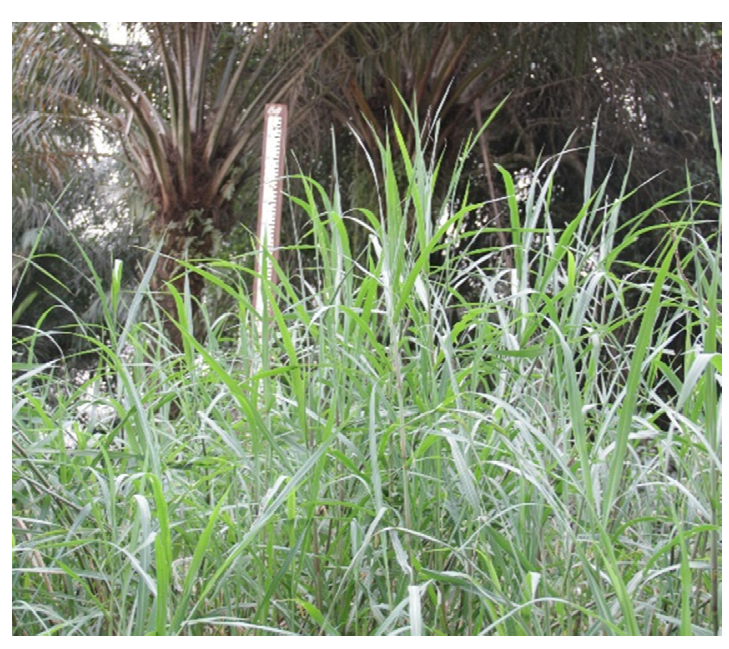

B. Staff gauge at Ebute Igboro

Figure 4. Typical Staff gauge restricted by vegetation growth (Source: Fieldwork, 2015)

\subsection{Analysis of Uncertainties Associated with Data Collection Challenges}

Gaps in hydrological time series result in reduced data completeness and shortened length, thereby contributing to uncertainties in flood frequency estimates, especially for the standard 1-in-100year flood estimate that has been proven to be significantly affected by the length of historical hydrological records (Feaster, 2010). These uncertainties propagate through to hydrodynamic models and consequently lead to flawed flood management decisions (Gill, Asefa, Kaheil, \& McKee, 2007). Figure 5 displays the number of hydrological records available for all five gauging stations from 1980/1982 to 2012 (30/32 years), revealing that data gaps varying from 4 to 7 years.

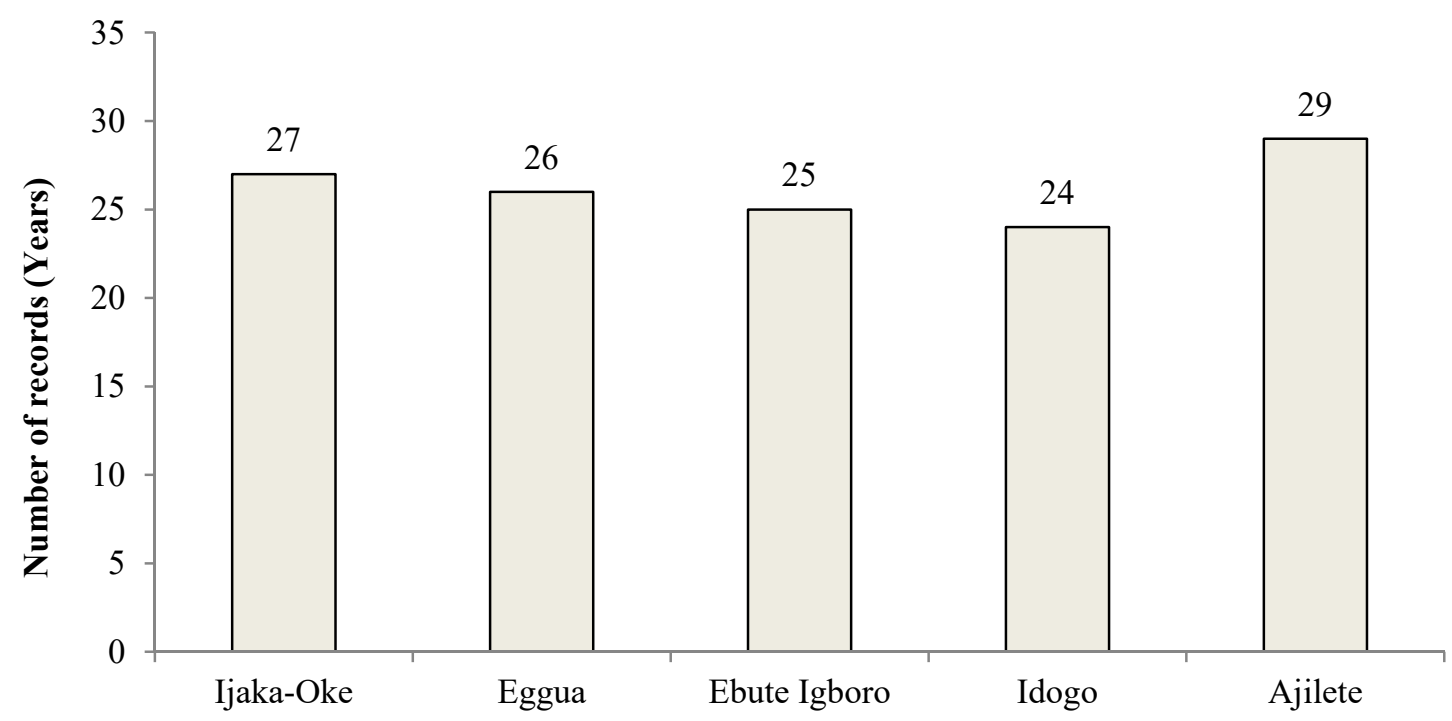

Gauging Stations

Figure 5. Graph showing the number of hydrological records available from Yewa River gauging station from 1980 to 2017 (Source: OORBDA)

To further understand the impact of missing data on flood estimates, an experimental analysis is undertaken using two datasets from Idogo station (Supplementary Figure 2) to estimate flood magnitudes from 1-in-2 year to 1-in-100 years return periods. For one of the data set, missing data removed (King, Honaker, Joseph, \& Scheve, 
1998) and for another, missing data is estimated using Monte Carlo multiple imputation approach (Graham, Olchowski, \& Gilreath, 2007). The results are presented in

Table 3, Figure 6 and Figure 7 showing how gaps in the hydrological time series can lead to different flood estimates of up to 2 and $2.22 \mathrm{~m}^{3} / \mathrm{s}$ for high return periods of 1-in 50 to 1-in-100-year floods respectively, which implies for instance a $0.90 \mathrm{~m}$ river level addition to $5.43 \mathrm{~m}$ for a 1 -in 100 -year flood, based on the rating curve presented in Supplementary Figure 1. This increased water level can inundate roads, farmlands, and socio-economic and physical infrastructure. Also, flood estimates with missing data filled were consistently higher than those derived from data sets where gaps are removed, suggesting likely underestimation of flood quantiles when missing data exist.

Table 3. Flood frequency estimates at Idogo station, for data with gaps removed and another filled

\begin{tabular}{|c|c|c|c|c|}
\hline Return period & $\operatorname{Idogo}-\mathbf{w} / g f\left(\mathrm{~m}^{3} / \mathrm{s}\right)$ & $\operatorname{Idogo}-\mathrm{w} / \mathrm{gr}\left(\mathrm{m}^{3} / \mathrm{s}\right)$ & $\begin{array}{c}\text { Difference } \\
\text { (w/gf - w/gr) }\end{array}$ & Water level(m) \\
\hline 1-in-2 years & 12.13 & 12.38 & -0.25 & -0.68 \\
\hline 1-in-5 Years & 13.48 & 12.85 & 0.63 & 0.73 \\
\hline 1-in-20 years & 14.57 & 12.98 & 1.59 & 0.82 \\
\hline 1-in-50 Years & 15.00 & 13.00 & 2.00 & 0.87 \\
\hline 1-in-100 Years & 15.23 & 13.01 & 2.22 & 0.90 \\
\hline
\end{tabular}

$\mathbf{w} / \mathbf{g f}=$ with gaps filled (using multiple imputation), $\mathbf{w} / \mathrm{gr}=$ with gaps $\mathrm{removed}, \mathrm{m}^{3} / \mathrm{s}=$ cumecs

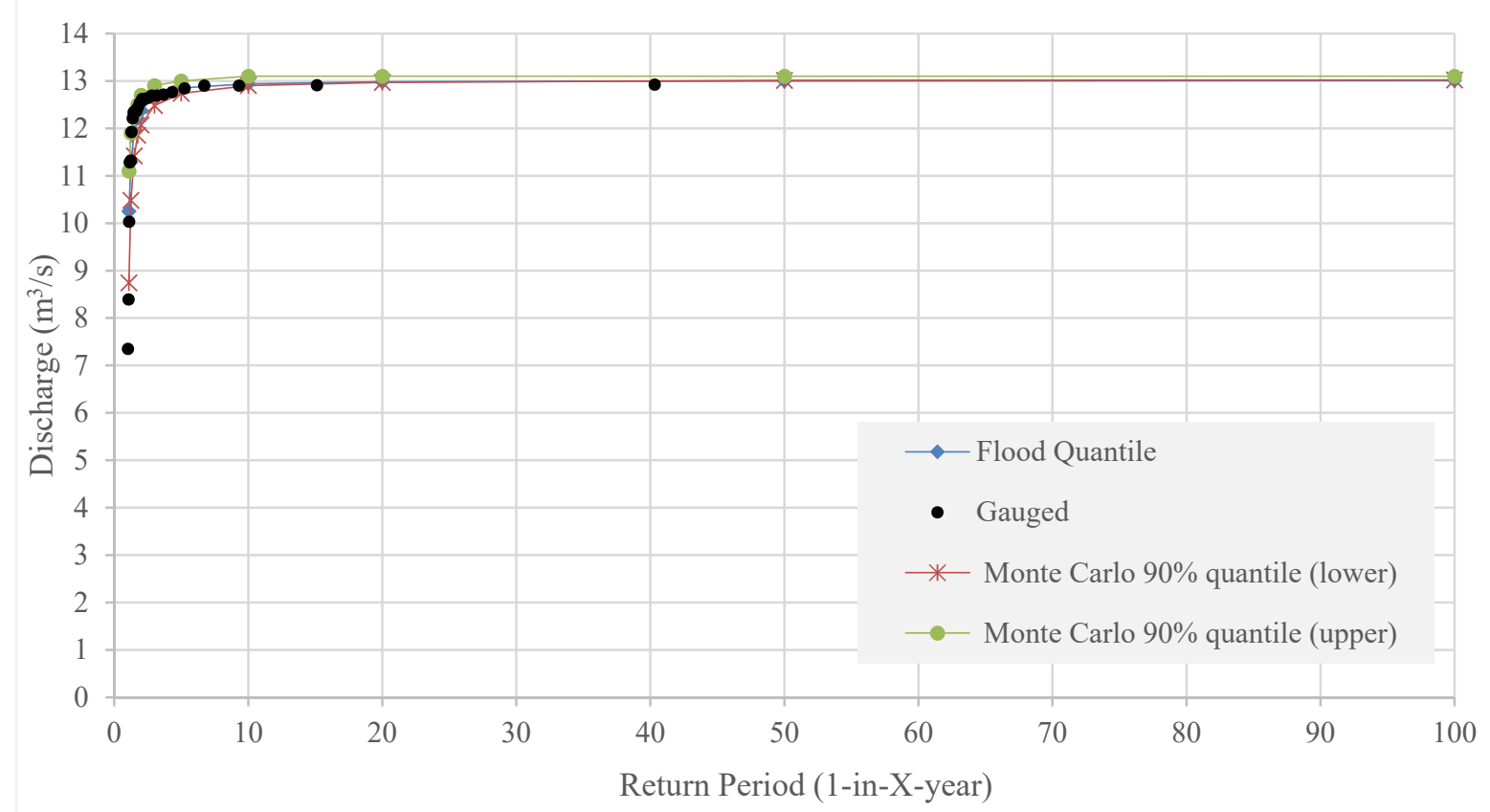

Figure 6. Flood frequency plot of Idogo station with gaps removed (w/gr) 


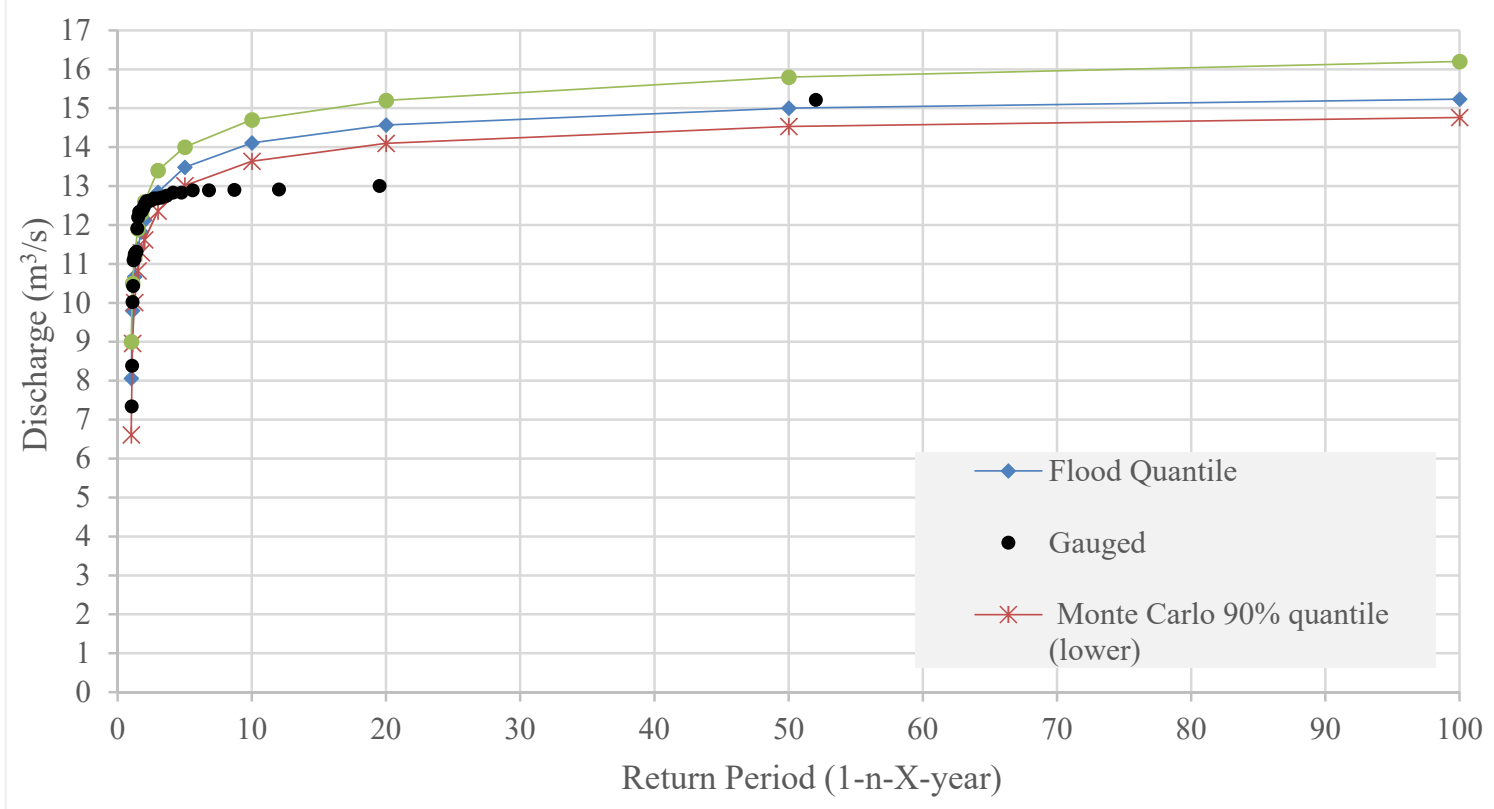

Figure 7. Flood frequency plot of Idogo station with gaps filled using multiple imputations (w/gf)

\section{Conclusion and Recommendations}

This study evaluated the challenges associated with hydrological data collection in a typical developing region based on gauge readers testaments, field observations and hydrological analysis, identifying capacity and institutional gaps; poor maintenance of hydrological equipment and surrounding landscape; poor data management architecture (collection, transmission, storage and format); and floods events that destroy hydrological equipment and inundate roads thus restricting access to data collection during peak floods, as factors that hamper seamless and sustainable data collection. These challenges result in data gaps in hydrological timeseries essential to flood frequency estimation during peak flood events, and shortened length of existing historical hydrological data, thereby causing aleatory uncertainty that propagates through flood modelling processes; and can affect flood estimates as demonstrated in this study. Furthermore, the use of gauge readers for the long-term may not be sustainable in the long-term, due to lack of an established succession plan, capacity building programmes and the current challenges of data collected during peak flow seasons. Also, a standardize and more accurate approach to hydrological data collection is recommended, possibly through the adoption of new technologies such as radar and Sonar automated systems for improved data collection and management, to enhance data transferability and usability in the Ogun-Osun River Basin.

\section{Acknowledgement}

The author is grateful to the Ogun-Osun River Basin authority for their support throughout this exercise, and provision of the data used in this study, as well as the five (5) gauge readers interviewed for this research. Also, I appreciate Mr David Goddey for facilitating the site visits and serving as interpreter and Mr Ayebapreye Ekeu-wei for recording and taking photographs during the fieldwork and interview sessions.

\section{References}

Adeaga, O., Oyebande, L., \& Depraetere, C. (2006). Surface runoff simulation for part of Yewa basin. Predictions in Ungauged Basins: Promise and Progress, (303), 382.

Adelekan, I. (2011). Vulnerability assessment of an urban flood in Nigeria: Abeokuta flood 2007. Nat Hazards, 56(1), 215-231. https://doi.org/10.1007/s11069-010-9564-z

Adeleke, O. O., Makinde, V., Eruola, A. O., Dada, O. F., Ojo, A. O., \& Aluko, T. J. (2015). Estimation of Groundwater Recharges Using Empirical Formulae in Odeda Local Government Area, Ogun State, Nigeria. Challenges, 6(2), 271-281. 
Aerts, J. C. J. H., Botzen, W. J. W., Emanuel, K., Lin, N., de Moel, H., \& Michel-Kerjan, E. O. (2014). Climate adaptation. Evaluating flood resilience strategies for coastal megacities. Science (New York, N.Y.), 344(6183), 473. https://doi.org/10.1126/science.1248222

Ampadu, B., Chappell, N. A., \& Kasei, R. A. (2013). Rainfall-Riverflow modelling approaches: making a choice of data-based mechanistic modelling approach for data limited catchments: A review. Canadian Journal of Pure and Applied Sciences, 7(3), 2571-2580.

Awokola, O., \& Martins, O. (2001). Regional Flood Frequency Analysis of Osun Drainage Basin, South-Western Nigeria. Nigerian Journal of Science, 35, 37-44.

Baldassarre, G. D., \& Montanari, A. (2009). Uncertainty in river discharge observations: a quantitative analysis. Hydrology and Earth System Sciences, 13(6), 913-921.

Bashiru, A. (2015). Field Work for: Flooding and Hydrological data collection - Lessons from gauge readers experiences and field observations. In I. T. Ekeu-wei (Ed.).

Beall, J. (2006). Metadata and data quality problems in the digital library. Journal of Digital Information, 6(3).

Dano Umar, L., Abdul-Nasir, M., Ahmad Mustafa, H., Imtiaz Ahmed, C., Soheil, S., Abdul-Lateef, B., \& Haruna Ahmed, A. (2011). Geographic Information System and Remote Sensing Applications in Flood Hazards Management: A Review. Research Journal of Applied Sciences, Engineering and Technology, 3(9), 933-947.

Di Baldassarre, G., Laio, F., \& Montanari, A. (2012). Effect of observation errors on the uncertainty of design floods. Physics and Chemistry of the Earth, 42-44, 85-90. https://doi.org/10.1016/j.pce.2011.05.001

Di Baldassarre, G., Montanari, A., Lins, H., Koutsoyiannis, D., Brandimarte, L., \& Blöschl, G. (2010). Flood fatalities in Africa: From diagnosis to mitigation. Geophysical Research Letters, 37(22). https://doi.org/ 10.1029/2010GL045467

Ertuna, C. (1995). Water Resources Development and Management in Asia and the Pacific. Environmental Soil and water Management: Past Experience and Future Directions, pp1-36.

Ewemoje, T. A., \& Ewemooje, O. (2011). Best distribution and plotting positions of daily maximum flood estimation at Ona River in Ogun-Oshun river basin, Nigeria. Agricultural Engineering International: CIGR Journal, 13(3).

Feaster, T. D. (2010). Importance of Record Length with Respect to Estimating the 1-Percent Chance Flood.

Gill, M. K., Asefa, T., Kaheil, Y., \& McKee, M. (2007). Effect of missing data on performance of learning algorithms for hydrologic predictions: Implications to an imputation technique. Water resources research, 43(7).

Graham, J., Olchowski, A., \& Gilreath, T. (2007). How Many Imputations are Really Needed? Some Practical Clarifications of Multiple Imputation Theory. Prev Sci, 8(3), 206-213. doi: 10.1007/s11121-007-0070-9

Haque, M. M., Rahman, A., \& Haddad, K. (2014). Rating Curve Uncertainty in Flood Frequency Analysis: A Quantitative Assessment. Journal of Hydrology and Environment Research, 2(1), 50-58.

Herschy, R. W. (2008). Streamflow measurement (3rd ed. ed.): New York : Taylor \&amp; Francis.

Hipel, K. (1995). Stochastic and statistical methods in hydrology and environmental engineering. Stochastic Hydrology and Hydraulics, 9(1), 1-11.

Honaker, J., King, G., \& Blackwell, M. (2011). Amelia II: A program for missing data. Journal of statistical software, 45(7), 1-47.

Izinyon, O., \& Ehiorobo, J. (2014). L-moments approach for flood frequency analysis of river Okhuwan in Benin-Owena River basin in Nigeria. Nigerian Journal of Technology, 33(1), 10-18.

Jinadu, A. M. (2015). The Challenges of Flood Disaster Management in Nigeria. Paper presented at the 2nd World Congree on DIsaster Management, Visakhapatman, Andhra Pradesh, India. Retrieved from http://www.wcdm.info/Compenium/other/2.FULL\%20LENGTH\%20PAPER-Mr.A.M.JINADU---NIG ERIA.pdf

King, G., Honaker, J., Joseph, A., \& Scheve, K. (1998). List-wise deletion is evil: what to do about missing data in political science. Paper presented at the Annual Meeting of the American Political Science Association, Boston. 
Komi, K., Neal, J., Trigg, M. A., \& Diekkrüger, B. (2017). Modelling of flood hazard extent in data sparse areas: a case study of the Oti River basin, West Africa. Journal of Hydrology: Regional Studies, 10, 122-132. https://doi.org/10.1016/j.ejrh.2017.03.001

Komolafe, A. A. B. S. A.-A. B. F. O. (2015). A Review of Flood Risk Analysis in Nigeria. American journal of environmental sciences., 11(3), 157.

Kuczera, G. (1999). Comprehensive at - site flood frequency analysis using Monte Carlo Bayesian inference. Water Resources Research, 35(5), 1551-1557. https://doi.org/10.1029/1999WR900012

Laio, F., Di Baldassarre, G., \& Montanari, A. (2009). Model selection techniques for the frequency analysis of hydrological extremes. Water Resources Research, 45(7), n/a-n/a. https://doi.org/10.1029/2007WR006666

Lavender, S. L., \& Matthews, A. J. (2009). Response of the West African monsoon to the Madden- Julian oscillation. Journal of climate, 22(15), 4097-4116. https://doi.org/10.1175/2009JCLI2773.1

Li, P., Stuart, E., \& Allison, D. (2015). Multiple Imputation A Flexible Tool for Handling Missing Data. Jama-Journal Of The American Medical Association, 314(18), 1966-1967.

Maxwell, O. (2013). Hydrological Data Banking for Sustainable Development in Nigeria: An Overview. Aceh International Journal of Science and Technology, 2(2).

Merz, B., \& Thieken, A. H. (2005). Separating natural and epistemic uncertainty in flood frequency analysis. Journal of Hydrology, 309(1), 114-132. https://doi.org/10.1016/j.jhydrol.2004.11.015

Olayinka, D. N. (2012). Modelling Flooding in The Niger Delta. (PhD), Lancaster University.

Olayinka, D. N., Nwilo, P. C., \& Emmanuel, A. (2013). From Catchment to Reach: Predictive Modelling of Floods in Nigeria.

Olomoda, I. (2012). Challenges of Continued River Niger Low Flow into Nigeria. Special Publication of the Nigerian Association of Hydrological Sciences, 145-155.

Ononiwu, N. (1994). Appraisal of the role of satellite systems in acquisition of data for monitoring and evaluating global climatic changes with respect to reservoir energy generation. Global Climate Change-Impact On Energy Development.[np]. 1994.

Padi, P. T., Baldassarre, G. D., \& Castellarin, A. (2011). Floodplain management in Africa: Large scale analysis of flood data. Physics and Chemistry of the Earth, 36(7), 292-298. doi: 10.1016/j.pce.2011.02.002

Smith, J. A., Villarini, G., \& Baeck, M. L. (2011). Mixture distributions and the hydroclimatology of extreme rainfall and flooding in the Eastern United States. Journal of Hydrometeorology, 12(2), 294-309. https://doi.org/10.1175/2010JHM1242.1

Starrett, S. K., Heier, T., Su, Y., Bandurraga, M., Tuan, D., \& Starrett, S. (2010). An Example of the Impact that Filled-In Peakflow Data Can Have on Flood Frequency Analysis. Paper presented at the World Environmental and Water Resources Congress2010@ sChallenges of Change.

van Buuren, S. (2007). Multiple imputation of discrete and continuous data by fully conditional specification. Statistical methods in medical research, 16(3), 219.

Villarini, G., \& Smith, J. A. (2010). Flood peak distributions for the eastern United States. Water Resources Research, 46(6), n/a-n/a. https://doi.org/10.1029/2009WR008395

Notes

Note 1. Staff Gauge is a measuring tool, similar to a tape measure, used to provide a visual indication of the depth of water (typically in a river, flume, or weir).

Note 2. The Case study site applied in the Flood Frequency Analysis for missing data impact evaluation

Note 3. http://floodobservatory.colorado.edu/Version3/MasterListrev.htm 


\section{Appendices}

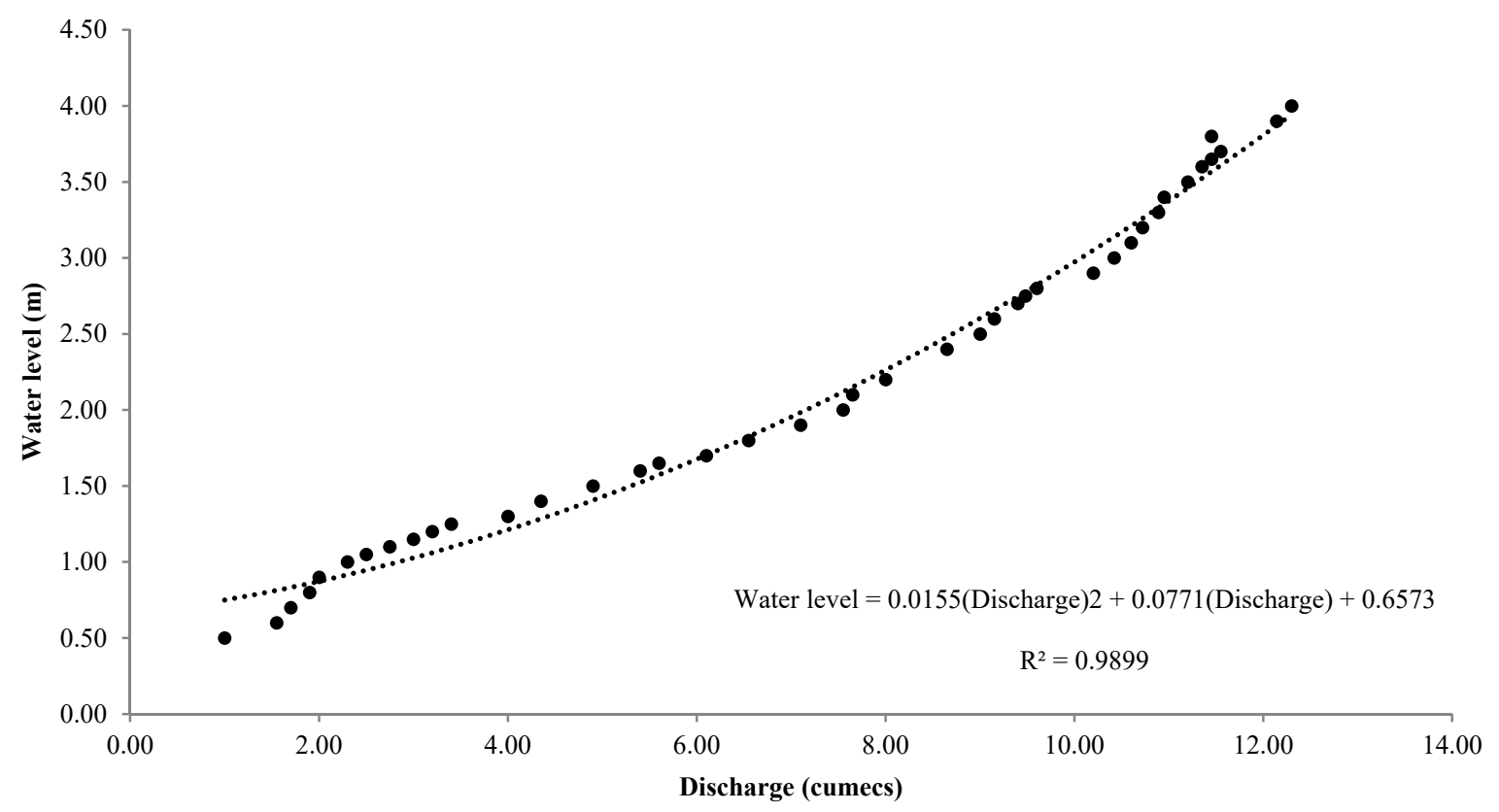

Supplementary Figure 1. Idogo Rating Curve (Source: OORBDA)

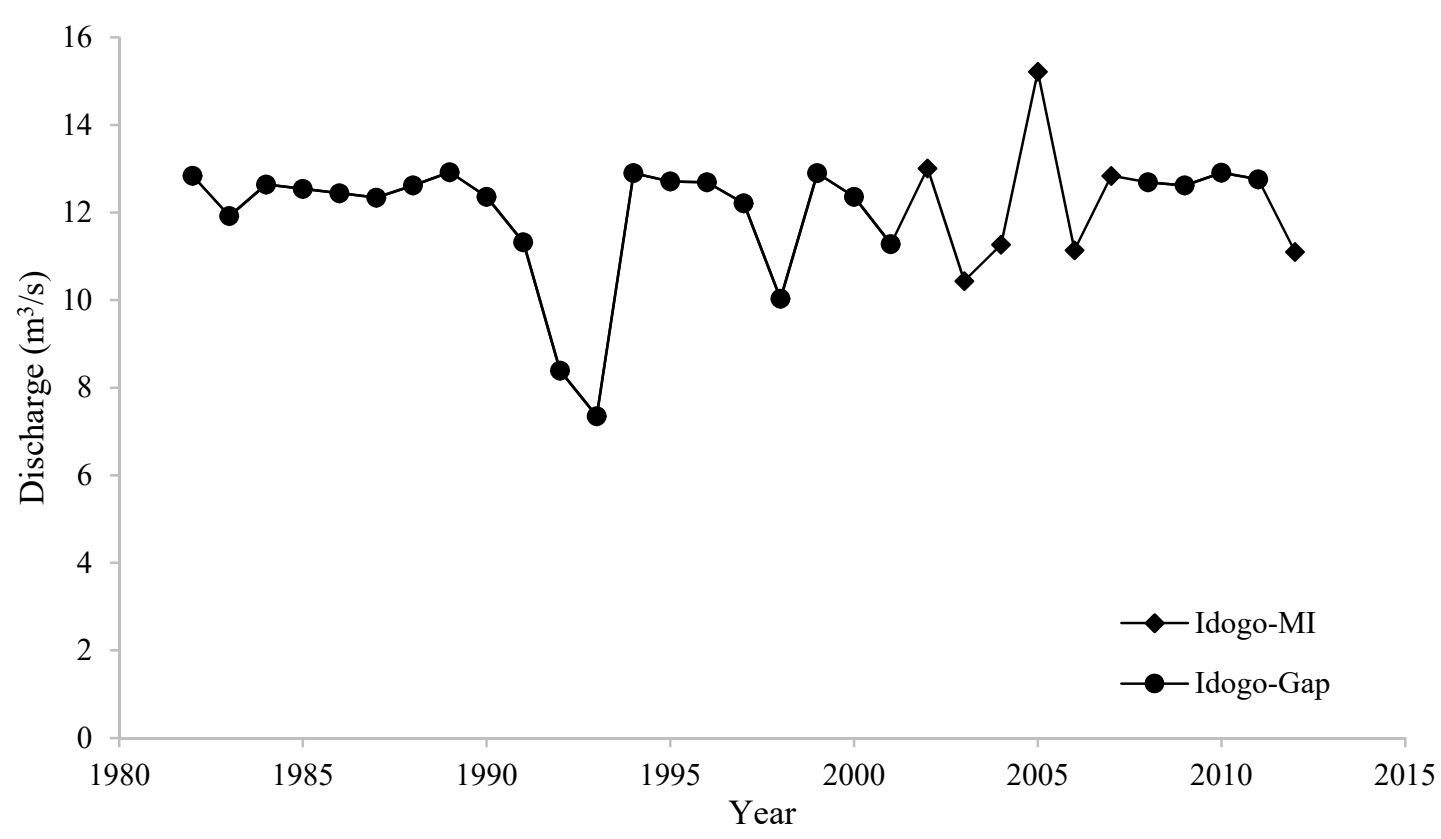

Supplementary Figure 2. Idogo Gauging Station Hydrological Time Series with missing data gaps and filled with Multiple Imputation (MI)

\section{Copyrights}

Copyright for this article is retained by the author(s), with first publication rights granted to the journal.

This is an open-access article distributed under the terms and conditions of the Creative Commons Attribution license (http://creativecommons.org/licenses/by/4.0/). 